\title{
TESTE DE FITOTOXICIDADE DO COMPOSTO ATRAZINA: BIOENSAIO UTILIZANDO COMO ORGANISMO TESTE A LACTUCA SATIVA
}

\author{
Daniel Ângelo Macena, Edna Antônia Torquato de Agostini, Tainá Tenório Costa, Rafaela Torquato \\ de Agostini
}

Universidade do Oeste Paulista - UNOESTE, Curso de Química, Presidente Prudente, SP. E-mail: daniel@unoeste.br.

\begin{abstract}
RESUMO
É muito importante a realização de testes toxicológicos com compostos químicos para conhecer os possíveis efeitos dos defensores agrícolas na saúde humana e impactos ambientais. A Atrazina é um herbicida do grupo das triazinas utilizada no controle de ervas daninhas e outras culturas. $O$ presente estudo teve como objetivo analisar a fitotoxicidade do composto Atrazina, através de bioensaio utilizando como organismo teste sementes de alface. Foi utilizado o teste de germinação para análise das possíveis alterações decorrentes do potencial toxicológico da Atrazina. Como resultados foi observado que a concentração de $0,6 \%$ de Atrazina foi considerada a concentração mínima que causa efeitos deletérios observáveis e $0,3 \%$ foi a concentração máxima que não causa efeitos deletérios. Conclui-se que a Atrazina de fato apresentou-se um forte potencial de toxicidade sobre a semente de alface, ao qual se tornou exponencial os efeitos causados diretamente na germinação das sementes.
\end{abstract}

Palavras-chave: Fitotoxicidade, Atrazina, Bioensaio, Lactuca Sativa.

\section{COMPOUND ATRAZINE PHYTOTOXICITY TEST: BIOASSAY USING LACTUCA SATIVA}

\begin{abstract}
It is very important to carry out toxicological tests with chemical compounds to know the possible effects of agricultural defenders on human health and environmental impacts. Atrazine is a triazine herbicide used to control weeds and other crops. The objective of the present study was to analyze the phytotoxicity of Atrazine compound by means of bioassay using lettuce seeds as test organism. The germination test was used to analyze the possible changes due to the toxicological potential of Atrazine. As results it was observed that the $0.6 \%$ concentration of Atrazine was considered the minimum concentration that causes deleterious observable effects and $0.3 \%$ was the maximum concentration that does not cause deleterious effects. It was concluded that Atrazine presented a strong toxicity potential on lettuce seed, to which the effects caused directly on the germination of the seeds became exponential.
\end{abstract}

Keywords: Phytotoxicity, Atrazine, Bioassay, Lactuca Sativa. 


\section{INTRODUÇÃO}

A Atrazina é um dos compostos mais difundidos e utilizados no mundo todo, sendo importante na chamada lavoura de conservação, pois aumenta a produtividade, diminuindo a erosão. Em altas concentrações é utilizada para matar todas as plantas vivas, por exemplo, para criar áreas de estacionamento de veículos. Os principais inconvenientes relacionados ao seu uso são a lixiviação e sua toxicidade intrínseca. Estima-se que 20 mil toneladas dessa substância são empregadas apenas na cultura canavieira no Brasil. O dado preocupante em relação à Atrazina, é devido á sua persistência e o seu potencial de escoamento nos solos, é um potencial contaminador de água (BREDA,2004).

A EPA (Environmental Protection Agency - Agência de Proteção Ambiental dos Estados Unidos) inclui a Atrazina como possível agente carcinógeno humano, uma vez que tem atividade endócrina. Alguns estudos mostraram que a exposição á Atrazina combinada com outros pesticidas aumentou o risco do surgimento de linfomas não-Hodkin's e de cânceres na bexiga e no pulmão (SOUSA, 2016), além de mielomas múltiplos em trabalhadores rurais (FREEMAN et al., 2011).

A remoção e/ou degradação de diversos poluentes orgânicos xenobióticos no ambiente não é uma atividade fácil. Em geral os processos biológicos são os menos onerosos, mas requerem a presença de organismos com o potencial de biotransformação ou biossorção e de condições especiais para que ocorram. A Atrazina é recalcitrante e uma das alternativas para remoção dessa substância é por barreiras usando trincheiras, aterros ou óleos vegetais. Essas barreiras impedem que a substância seja carregada por fluxo de águas (HUNTER e SHANER, 2010).

Esses mecanismos de remoção dependem da característica de cada matriz como teor de matéria orgânica, textura, umidade, entre outros. Outro mecanismo de remoção é o uso de minhocas (Eisenia foetida) que são capazes de adsorver estes compostos, no entato esses organismos apresentam sensibilidade a Atrazina (PANINI e ANDRÉA, 2001). O que dificulta na solução da degradação que o composto exerce sobre o solo.

À frente do problema de degradação ambiental, se faz necessário levantar todas as informações sobre a composição química e o efeito que esses herbicidas têm nos organismos vivos. Dentre os bioensaios realizados para esta finalidade, aqueles que utilizam vegetais como modelos biológicos se destacam, pois são fáceis de realizar e o custo é baixo.

A alface (Lactuca sativa L. - Asteraceae) tem sido amplamente utilizada em testes de fitotoxicidade (DING et al., 2010 e genotoxicidade (MONTEIRO et al., 2009; EOM et al., 2007) devido á sua sensibilidade e representatividade, e ainda por ser amplamente cultivada no mundo todo, a avaliação de danos sobre o complemento cromossômico da alface é favorecida pelo fato da espécie possuir características citogenéticas estáveis e bem definidas, como cromossomos grandes e em número reduzido ( $2 n=2 x=18$ ) (CAMPOS et al., 2008).

A alface é a folhosa mais consumida no Brasil e a terceira hortaliça em maior volume de produção, ficando atrás da melancia e o tomate apenas, segundo a Associação Brasileira do Comércio de Sementes e Mudas (ABCSEM, 2016).

A interação do herbicida com a planta ocorre devido à capacidade de transporte $\mathrm{e}$ absorção dela e qual o potencial contaminante envolvido. Os contaminantes quando absorvidos pela planta tendem a serem imobilizados e/ou acumulados no seu interior e removidos ou não pós-colheita (PINHEIRO, 2011).

Diante do contexto apresentado, o presente trabalho tem como objetivo analisar a fitotoxicidade do composto Atrazina, através de bioensaio utilizando como organismo teste sementes de alface (Lactuca sativa). 


\section{METODOLOGIA}

\section{Preparo e higienização dos materiais}

Os materiais utilizados nos experimentos receberam limpeza adequada e esterilização em Estufa a $180^{\circ} \mathrm{C}$ por 2 horas.

O material que foi utilizado no laboratório com Atrazina foram limpos com detergente neutro, repassados com água corrente e posteriormente recebeu banho de acetona (concentração igual a 50\%) e água destilada suficiente para remoção de todo o resíduo, além de posterior secagem em estufa a $180^{\circ} \mathrm{C}$ por 2 horas.

\section{PROCEDIMENTO EXPERIMENTAL}

Para o desenvolvimento experimental foram utilizadas 10 concentrações diferentes do composto Atrazina, 25\%; 20\%; 15\%; 10\%; 5\%; 2,5\%; 1,25\%; 0,6\%; 0,3\%, e um teste controle, onde a diluição do composto procedeu-se através da adição de água de água destilado com auxílio de uma proveta para medir e aferir o volume final desejado.

Para maior confiabilidade dos resultados os testes foram realizados em quatro réplicas, totalizando 40 gerbox, onde foram dispostas 25 sementes de alface Lactuca sativa, que serviram como organismo teste de fitotoxicidade do composto Atrazina que foi utilizado em solução, utilizando as diferentes concentrações de $25 \%$ a $0,3 \%$ do composto e controle ao qual foi utilizado $13 \mathrm{~mL}$ de cada solução em cada gerbox, de modo a auxiliar na avaliação da maior concentração em que não se observa efeitos deletérios (CENO) Concentração de Efeitos Não Observáveis, e a menor concentração onde se observa efeitos deletérios, (CEO) Concentração de Efeitos Observáveis.

As sementes ficaram expostas ao herbicida durante o período de 120 horas, após completar o tempo determinado do início do teste foi realizada uma leitura para verificação da porcentagem de inibição do crescimento da semente nas diferentes concentrações do composto.

Com temperatura controlada de $25^{\circ} \mathrm{C}$ com pequenas variações, e em luminosidade artificial disponibilizada pelas lâmpadas do próprio germinador, com foto período de 16 horas claro.

\section{RESULTADOS}

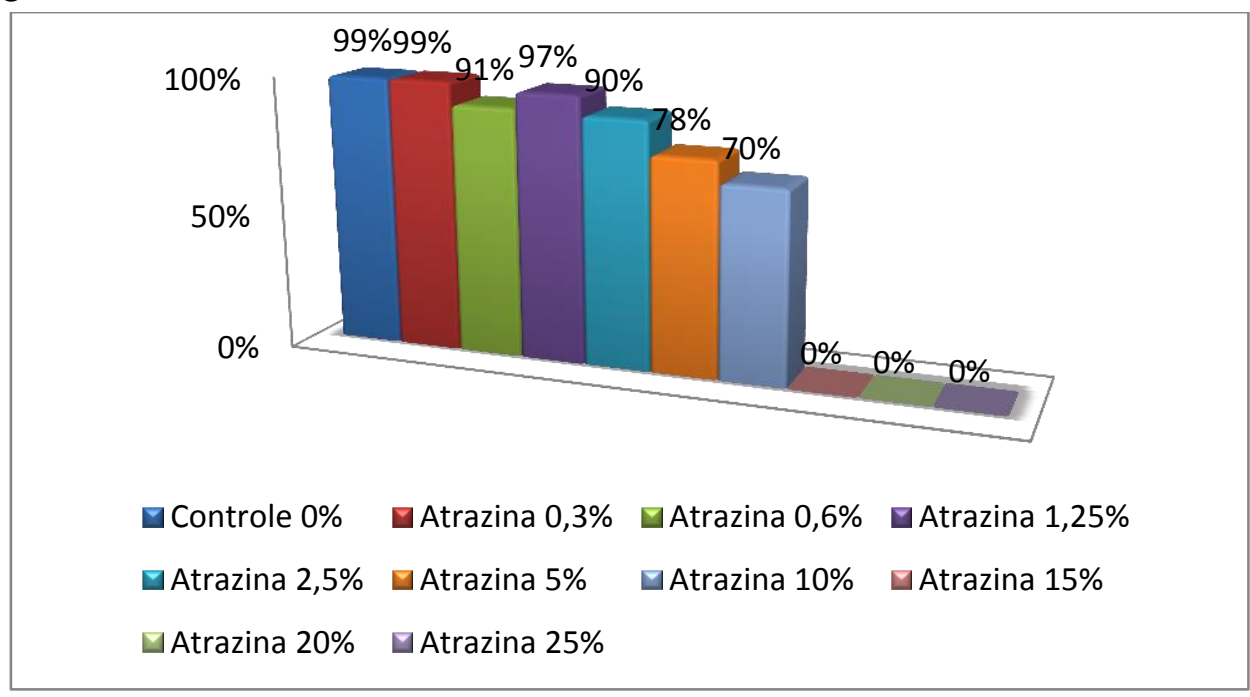

Gráfico 1. Porcentagem de germinação normal das sementes de alface Fonte: Próprio autor

Foi avaliada a porcentagem de germinação de sementes, na sequência de plântulas normais na primeira contagem, plântulas anormais que são aquelas onde mesmo em condições favoráveis não há potencial para continuar se desenvolvendo e originar plantas normais segundo 
Brasil (1992); sementes mortas, as que ao final do teste não germinam, não estão dormentes e nem duras, normalmente ficam amolecidas e sem indícios de germinação (REIS; FILHO, 2013). Todos os resultados foram apresentados de forma gráfica como mostra a seguir os gráficos 1, 2 .

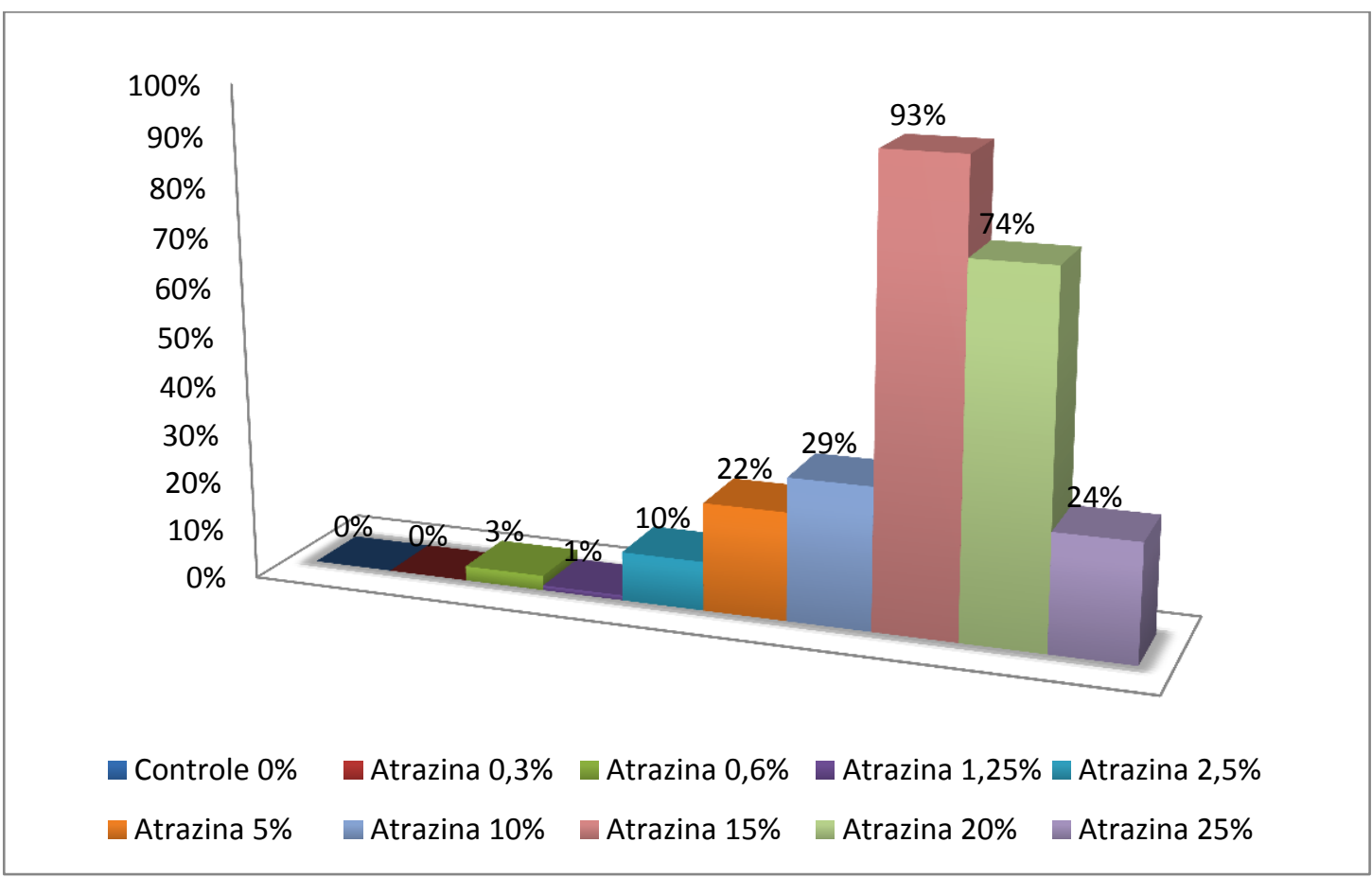

Gráfico 2. Porcentagem de germinação anormal das sementes de alface.

Fonte: Próprio autor

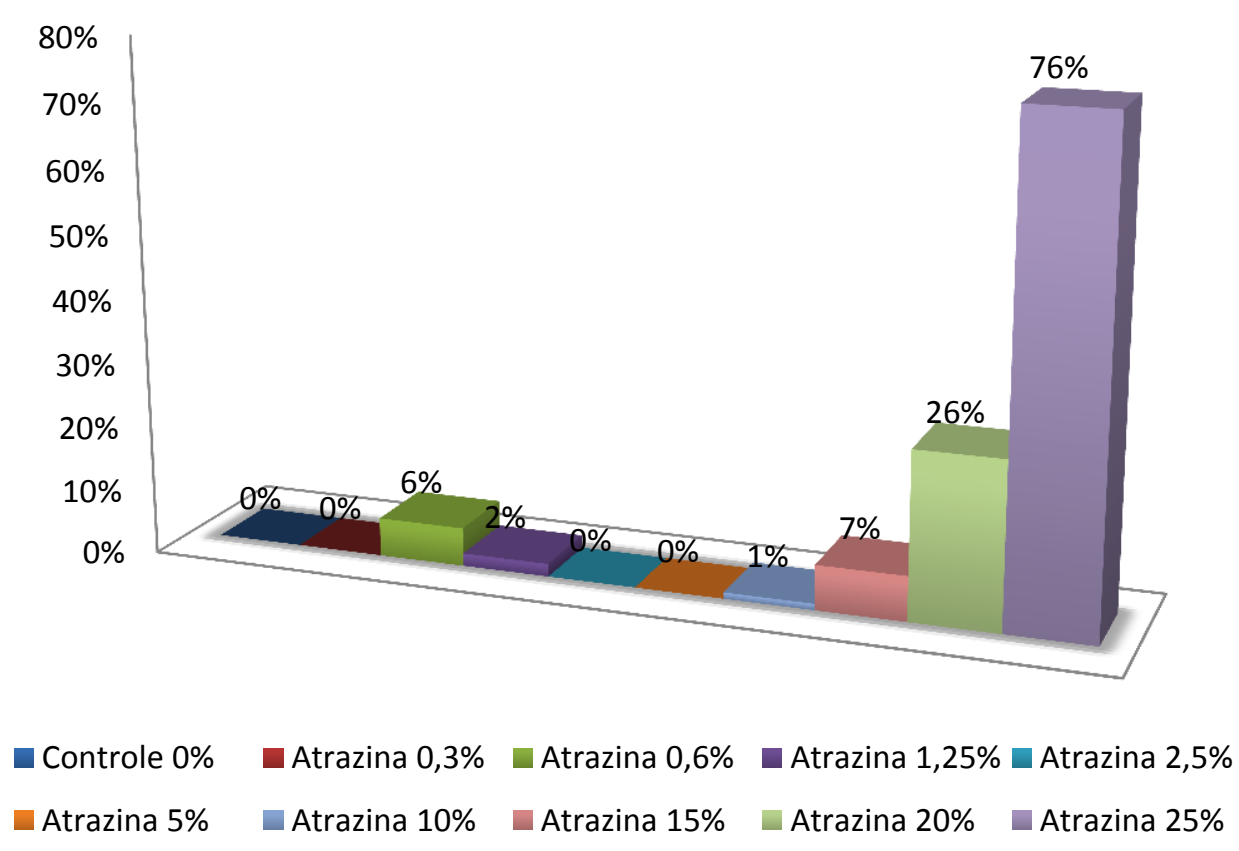

Gráfico 3. Porcentagem de morte das sementes de alface

Fonte: Próprio autor

\section{DISCUSSÃO}

Foi observado no Gráfico 1 que entre $0 \%$ e $0,3 \%$ não houve alterações quanto a germinação das sementes. A partir de $0,6 \%$ da presença do composto Atrazina começa a existir 
um decaimento na germinação normal das sementes. Percebeu-se também que na concentração de $1,25 \%$ houve certa resistência, enquanto que de $15 \%$ a $25 \%$ não houve vestígios de germinação de sementes normais.

No Gráfico 2 podemos perceber que inicia-se, assim como no Gráfico 1, alterações a partir da concentração de $0,6 \%$ do composto Atrazina, onde o que decaiu no primeiro gráfico, neste mesmo tratamento foi observado 3\% de sementes anormais. À medida que começa a decair no Gráfico 1, percebe-se um aumento nas sementes anormais, por exemplo, no tratamento das concentrações de 15 a $20 \%$ não apresenta germinação de sementes normais, enquanto que indica uma variação de $24 \%$ a $93 \%$ de sementes anormais.

No gráfico de porcentagens de sementes consideradas mortas (Gráfico 3) apresenta uma variação a partir da concentração de $0,6 \%$, onde observa-se que as sementes mortas neste tratamento foi duas vezes maiores que sementes anormais. Nas concentrações de $15 \%$ a $25 \%$ houve uma variação entre $7 \%$ e $76 \%$ de sementes mortas.

Visto que os gráficos apresentam diferentes variações entre sementes germinadas normais, anormais e mortas pode-se então classificar o CEO e CENO dos resultados apresentados graficamente sobre a exposição ao composto Atrazina e seu potencial toxicológico. Relacionando os três gráficos é possível perceber que a partir da exposição da semente de alface na concentração de $0,6 \%$ da Atrazina em solução, começa a causar efeitos observáveis deletérios, ou seja essa é considerada a concentração mínima que causa efeitos deletérios observáveis (CEO), pois a $0,6 \%$ já é observado anormais e/ou mortas. Posteriormente, pode-se concluir que a concentração máxima que não causa efeitos deletérios (CENO) nas sementes de alface é a de $0,3 \%$, foi observado que apresentou o mesmo resultado que o controle, $0 \%$ do composto Atrazina em solução.

Um estudo por Régo e colaboradores (2017), mostra que a Lactuca sativa é uma ótima ferramenta indicadora ambiental, visto que utilizaram diferentes organismos no ensaio de fitotoxicidade e a Lactuca sativa foi a mais sensível nos resultados. Os autores expos a Lactuca sativa ao herbicida Gesapax no qual inibiu o crescimento e germinação das sementes, sendo que a inibição ao crescimento foi mais significativa conforme o aumento das concentrações do herbicida. Neste sentido corrobora com a escolha do organismo teste no presente trabalho em relação a maior sensibilidade nos resultados.

Na pesquisa de Welter et al. (2016) foi avaliado a toxicidade e a biodegradabilidade de amostras de um lixiviado de aterro sanitário (LAS) tratado pela reação Foto-Fenton utilizando ácido cítrico como agente complexante a partir da Lactuca sativa como organismo teste. Como resultado os testes de fitotoxicidade confirmaram os benefícios da reação ferricitrato na oxidação de compostos inicialmente tóxicos ( $C L$ 50=15\%), uma vez que a CL50 evoluiu para aproximadamente 53\%. Observa-se que a Lactuca Sativa é utilizada tanto para estudos que comprovam efeitos benéficos quanto aos potenciais efeitos maléficos.

\section{CONCLUSÃO}

Pode-se perceber no presente estudo que o teste de fitotoxicidade é uma ótima ferramenta na pesquisa em se tratando de possíveis efeitos deletérios causados decorrentes de potenciais contaminantes assim como, estudar benefícios que podem ser respostas a partir de outros estudos, tais como, o Processo Oxidativo Avançado que avalia a eficiência na degradação de compostos potencialmente tóxicos.

Conclui-se que a Atrazina de fato apresentou-se um forte potencial de toxicidade sobre a semente de alface, ao qual se tornou exponencial os efeitos causados diretamente na germinação das sementes. Sugere-se futuro bioensaio utilizando outra planta sensível ao teste de micronúcleo para estudos de possíveis alterações genéticas decorrentes do herbicida Atrazina. 


\section{REFERÊNCIAS}

ABCSEM - Associação Brasileira do Comércio de Sementes e Mudas. O Mercado de Folhosas: Números e Tendências. Seminário Nacional de Folhosos. Campinas - SP. 2016. Disponível em: http://www.abcsem.com.br/upload/arquivos/O_mercado_de_folhosas_Numeros_e_Tendencias _-_Steven.pdf . Acesso em: 28 jul 2017.

BRASIL, Ministério da Agricultura e Reforma Agrária. Regras para análise de sementes. Brasília: DNDV/CLAV, 1992. $365 \mathrm{p}$

BREDA, T. 2004. Biorremédio é mais eficiente na degradação de herbicidas no solo. USP Notícias Meio Ambiente. Disponível em: http://www.renorbio.org.br/portal/noticias/biorremedio-e-maiseficiente-na-degradacao-de-herbicidas-no-solo.htm . Acesso em: 28 jul. 2017.

CAMPOS, J. M. S. et al. Mutagenic effects due to allelopathic action of fern (Gleicheniaceae) extracts. Allelopathy Journal, v. 22, n. 1, p. 143-152, 2008.

DING, Lan et al. Regulation of cell division and growth in roots of Lactuca sativa L. seedlings by the ent-kaurene diterpenoid rabdosin B. Journal of chemical ecology, v. 36, n. 5, p. 553-563, 2010.

EOM, I. C. et al. Ecotoxicity of a polycyclic aromatic hydrocarbon (PAH)-contaminated soil. Ecotoxicology and environmental safety, v. 67, n. 2, p. 190-205, 2007, https://doi.org/10.1016/i.ecoenv.2006.12.020.

FREEMAN, Laura E. Beane et al. Atrazine and cancer incidence among pesticide applicators in the agricultural health study (1994-2007). Environmental health perspectives, v. 119, n. 9, p. 1253, 2011.

HUNTER, William J.; SHANER, Dale L. Biological remediation of groundwater containing both nitrate and atrazine. Current microbiology, v. 60, n. 1, p. 42, 2010, https://doi.org/10.1007/s00284-009-9499-3.

MONTEIRO, M. S. et al. Microsatellite instability in Lactuca sativa chronically exposed to cadmium. Mutation Research/Genetic Toxicology and Environmental Mutagenesis, v. 672, n. 2, p. 90-94, 2009, https://doi.org/10.1016/i.mrgentox.2008.10.012.

PAPINI, S.; ANDRÉA, M. M. Dissipação de simazina em solo por ação de minhocas (Eisenia foetida). Revista brasileira de ciência do solo, v. 25, n. 3, 2001, https://doi.org/10.1590/S0100$\underline{06832001000300008 .}$

PINHEIRO, Adilson; MORAES, João; DA SILVA, Marcos R. Pesticidas no perfil de solos em áreas de plantação de cebolas em Ituporanga, SC. Revista Brasileira de Engenharia Agricola e AmbientalAgriambi, v. 15, n. 5, 2011.

RÉGO, Ana Paula Justiniano; BIDOIA, Ederio Dino; CONEGLIAN, Cassiana Maria Reganhan. Influência do herbicida Gesapax na atividade microbiana do solo e sua ecotoxicidade. Pósgraduação Ciências Biológicas (Microbiologia Aplicada) - IBRC. Tese de doutorado. Rio Claro - SP, 2017. Disponível em: <http://hdl.handle.net/11449/151088>. Acesso em: 04 ago 2017. 
REIS, J. D.; FILHO, R. M. ÁNALISES DE QUALIDADE DE SEMENTES DE SOJA. Universidade de Brasília. 2013.

Disponível

em:

http://bdm.unb.br/bitstream/10483/6682/1/2013_JulianaDiasDosReis.pdf.Acesso em: 28 jul 2017.

SOUSA, Rafaely Ximenes de. Degradação eletroquímica dos herbicidas atrazina e alaclor utilizando ânodo dimensionalmente estável comercial. 2016. Tese de Doutorado. Universidade de São Paulo.

WELTER, Júlia Bitencourt et al. AVALIAÇÃO DA FITOTOXICIDADE E DA BIODEGRADABILIDADE DE UM LIXIVIADO DE ATERRO SANITÁRIO TRATADO POR FOTO-FENTON INDUZIDO POR FERRICITRATO. Anais do SEPE-Seminário de Ensino, Pesquisa e Extensão da UFFS, v. 6, n. 1, 2016. 